\title{
Study on Effect of Rectangular DMS and DGS on 4 and 8 Elements Rectangular Microstrip Linear Array Antenna
}

\author{
S L Mallikarjun, P M Hadalgi and P V Hunagund \\ Microwave Laboratory, Dept. of PG Studies and Research in Applied Electronics, \\ Gulbarga University, Gulbarga - 585 106, Karnataka (INDIA). \\ mslakshetty@rediffmail.com

\begin{abstract}
In this experimental study a novel design has been developed to improve the antenna parameters in terms of impedance bandwidth and radiation properties. A 4-element rectangular array antenna (refereed as antenna 1) operating in the range of 10 to $16 \mathrm{GHz}$ with multi bands is used as a reference antenna. The impedance bandwidth and other radiation properties have been enhanced by using defected microstrip structure (DMS) and defected ground structure (DGS). This study is further extended to 8-element array. The design consideration and experimental results of the proposed antennas are presented and discussed.
\end{abstract}

Index Terms - DMS, DGS, impedance bandwidth, radiation properties

\section{INTRODUCTION}

Microstrip patch antennas are the new generation of the antennas due to their low profile, inexpensive to manufacture and easy to integrate with monolithic microwave integrating circuit (MMICs) design [1]. However the main disadvantage of the microstrip patch antenna is their narrow impedance bandwidth and excitation of the surface wave. The input impedance of the antenna tends to be sensitive to change in frequency; hence the deviation of the antenna input impedance from a real fixed value often determines the operating range of the antenna. The input impedance of the antenna depends on its geometrical shape, dimension and feed type. Therefore, the antenna input impedance is a very important design parameter, which controls the radiating power and impedance bandwidth.

In certain applications, such as high data-rate wireless transmission, this low bandwidth is not adequate. In order to meet the demand for large bandwidth, several techniques have been reported, the most commonly employed technique is increasing the thickness of the substrate supporting the microstrip patch. However limitations still exist on the ability to effectively feed the patch on a thick substrate and the radiation efficiency can degrade with increasing substrate thickness [2]. Techniques for overcoming this band limiting problem can be achieved using the parasitic tuning elements, external matching and separating the feed and the antenna. 
Impedance bandwidth and radiation properties of microstrip antenna (MSA) are also enhanced by using DMS and DGS. Defected ground structure was first proposed by Park et.al., based on the idea of photonic band-gap (PBG) structure, and had found its application in the design of planar circuits and low pass filters [3]. DGS and DMS is realized by etching a specific pattern in the ground plane of the microstrip structure(DGS) or on the microstrip surface (DMS), DGS disturbs the shield current distribution in the ground plane. This disturbance can change the characteristic of a transmission line such as equivalent capacitance and inductance to obtain the slow-wave effect and band-stop property [4]. Due to insertion of DGS/DMS there is an additional inductance occurs due to the magnetic flux flow in the etched out aperture and gap capacitance on ground plane. Surface impedance is changed due to an etched defect which in turn disturbs the shield current distribution in the plane. The change in surface impedance changes its phase velocity of the current. The change in phase velocity leads in change in the apparent effective permittivity.

Many shapes of DGS slot have been studied for single element microstrip antenna such as circle, dumbbells and spiral. Recently for 2 element array a hexagonal DGS is studied [5], however not many have realized it in antenna arrays.

In this experimental study, a novel design has been developed by using DMS and DGS. A 4element rectangular microstrip array antenna (antenna 1) operating in the range of 10 to $16 \mathrm{GHz}$ resonating for multi bands has been used as a reference antenna. It has been observed from the detailed study that by using DMS and DGS impedance bandwidth and other radiation properties are improved. Further the study is extended to 8-element rectangular microstrip array antenna.

\section{ANTENNA CONFIGURATION}

The proposed antennas are designed using low cost glass epoxy material having dielectric constant $\epsilon_{r}=4.2$, thickness $h=0.166 \mathrm{~cm}$ and loss tangent $\tan \delta=0.02$. The geometry of antenna 1 is shown in Fig. 1.

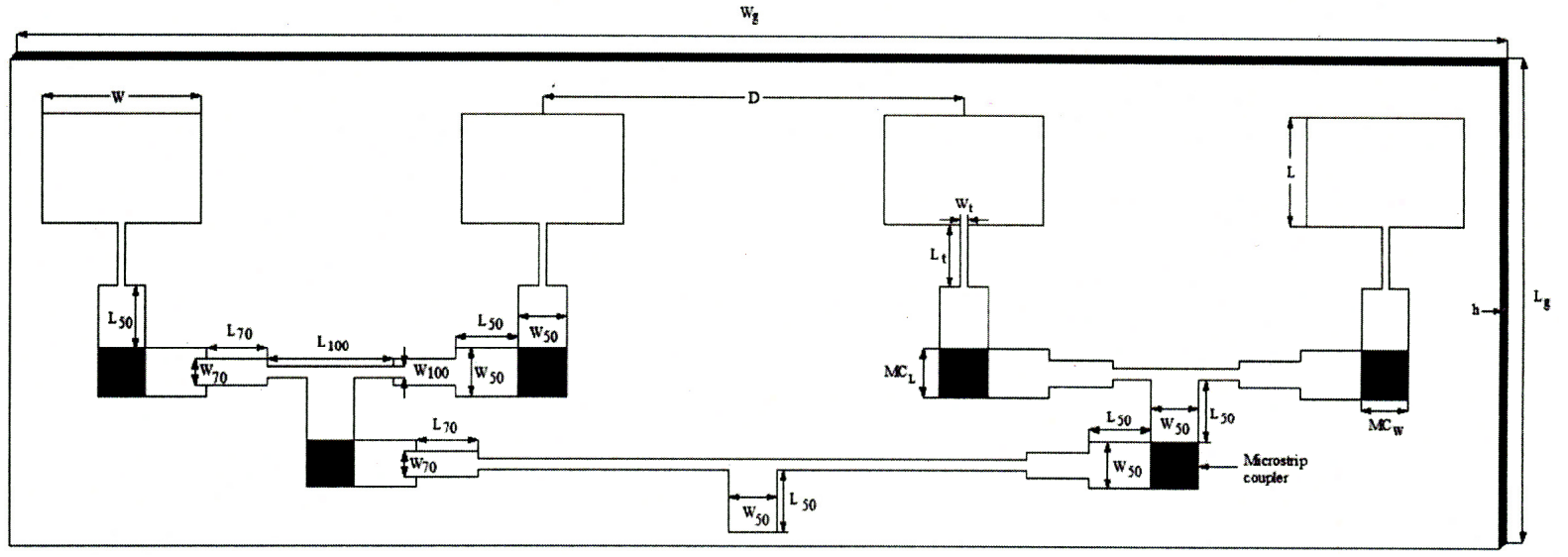

Fig. 1. Geometry of antenna 1

Brazilian Microwave and Optoelectronics Society-SBMO Brazilian Society of Electromagnetism-SBMag received 1 June, 2010; revised 7 Oct., 2010; revised 10 Jan., 2011; accepted 18 Jan., 2011

(C) 2011 SBMO/SBMag 
The elements of array are designed for $9.4 \mathrm{GHz}$ frequency with dimensions $L$ and $W$. The length $L_{g}$ and $W_{g}$ of the ground plane of antenna is calculated using $L g=6 h+L$ and $W g=6 h+\mathrm{W}$ [6]. The elements of this array antenna are excited through simple corporate feed arrangement. This feed arrangement consists of matching transformer, quarter wave transformer, microstrip coupler and power divider for better impedance matching between feed and radiating elements [7]. A two-way power divider made up of $70 \Omega$ matching transformer of dimension $\left(L_{70}, W_{70}\right)$ is used between $100 \Omega$ microstrip line of dimension $\left(L_{100}, W_{100}\right)$ and $50 \Omega$ microstrip line of dimension $\left(L_{50}, W_{50}\right)$. A microstrip coupler of dimension $\left(M C_{L}, M C_{W}\right)$ is used between $50 \Omega$ microstrip lines to couple the power [8], [9]. The $50 \Omega$ microstrip line is connected at the center of the driven element through a quarter wave transformer of dimension $\left(L_{t}, W_{t}\right)$ for better impedance matching. At the tip of microstrip line feed of $50 \Omega$, a coaxial SMA connector is used for feeding the microwave power. The array elements are kept at a distance of $D=5 \lambda_{0} / 6$ from their center point, where $\lambda_{0}$ is the free space wavelength in centimeters. This optimized distance is selected in order to achieve minimum side lobes in the radiation pattern and to add the radiated power in free space. The various dimensions mentioned in Fig. 1, Fig. 2 and Fig. 3 are given in table I.

TABLE I - DIMENSIONS OF PATCH, CORPORATE FEED LINE NETWORK, DMS and DGS

\begin{tabular}{|l|l|}
\hline Length of the patch $(L)$ & $0.66 \mathrm{~cm}$ \\
\hline Width of the patch $(W)$ & $0.98 \mathrm{~cm}$ \\
\hline $\begin{array}{l}\text { Length of ground plane of antenna } 1 \text { and antenna } \\
2(L g)\end{array}$ & $4.06 \mathrm{~cm}$ \\
\hline $\begin{array}{l}\text { Width of ground plane of antenna } 1 \text { and antenna } 2 \\
(W g)\end{array}$ & $11.41 \mathrm{~cm}$ \\
\hline $\begin{array}{l}\text { Length of ground plane of antenna } 3 \text { and antenna } \\
\text { 4 }(L g \text { ') }\end{array}$ & $5.30 \mathrm{~cm}$ \\
\hline $\begin{array}{l}\text { Width of ground plane of antenna } 3 \text { and antenna } 4 \\
\text { (Wg') }\end{array}$ & $22.83 \mathrm{~cm}$ \\
\hline Length of $50 \Omega$ line $\left(L_{50}\right)$ & $0.41 \mathrm{~cm}$ \\
\hline Width of $50 \Omega$ line $\left(W_{50}\right)$ & $0.31 \mathrm{~cm}$ \\
\hline Length of $100 \Omega$ line $\left(L_{100}\right)$ & $0.83 \mathrm{~cm}$ \\
\hline Width of $100 \Omega$ line $\left(W_{100}\right)$ & $0.07 \mathrm{~cm}$ \\
\hline Length of $70 \Omega$ line matching transformer $\left(L_{70}\right)$ & $0.41 \mathrm{~cm}$ \\
\hline Width of $70 \Omega$ line matching transformer $\left(W_{70}\right)$ & $0.16 \mathrm{~cm}$ \\
\hline Length of microstrip coupler $\left(M C_{L}\right)$ & $0.32 \mathrm{~cm}$ \\
\hline Width of microstrip coupler $\left(M C_{W}\right)$ & $0.32 \mathrm{~cm}$ \\
\hline Length of quarter wave transformer $\left(L_{t}\right)$ & $0.42 \mathrm{~cm}$ \\
\hline Width of the quarter wave transformer $\left(W_{t}\right)$ & $0.05 \mathrm{~cm}$ \\
\hline Distance between two driven elements $(D)$ & $2.79 \mathrm{~cm}$ \\
\hline Length of DMS $\left(L_{D M S}\right)$ & $0.33 \mathrm{~cm}$ \\
\hline Width of DMS $\left(W_{D M S}\right)$ & $0.22 \mathrm{~cm}$ \\
\hline Length of DGS $\left(L_{D G S}\right)$ & $0.011 \mathrm{~cm}$ \\
\hline Width of DGS $\left(W_{D G S}\right)$ & $0.025 \mathrm{~cm}$ \\
\hline
\end{tabular}

Fig. 2 shows the process of building the new DMS and DGS shaped array antenna (referred as antenna 2). To increase the impedance bandwidth of antenna 1, the last two elements of array are modified by inserting four rectangular DMS with same dimensions $L_{D M S}$ and $W_{D M S}$ as given in table I, at the edges of last two radiating patch [10]. To shift the frequency and to suppress the surface wave, a Brazilian Microwave and Optoelectronics Society-SBMO received 1 June, 2010; revised 7 Oct., 2010; revised 10 Jan., 2011; 
rectangular DGS of dimension $L_{D G S}$ and $W_{D G S}$ as given in table I is used exactly below all the four elements [11].

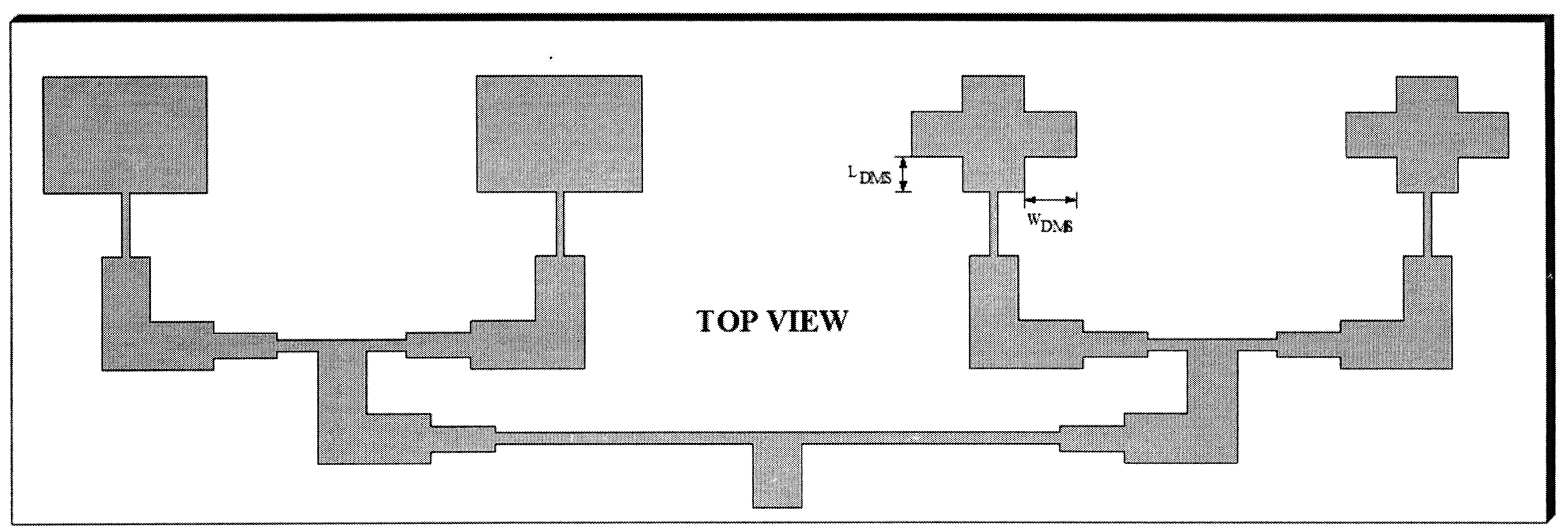

(a)

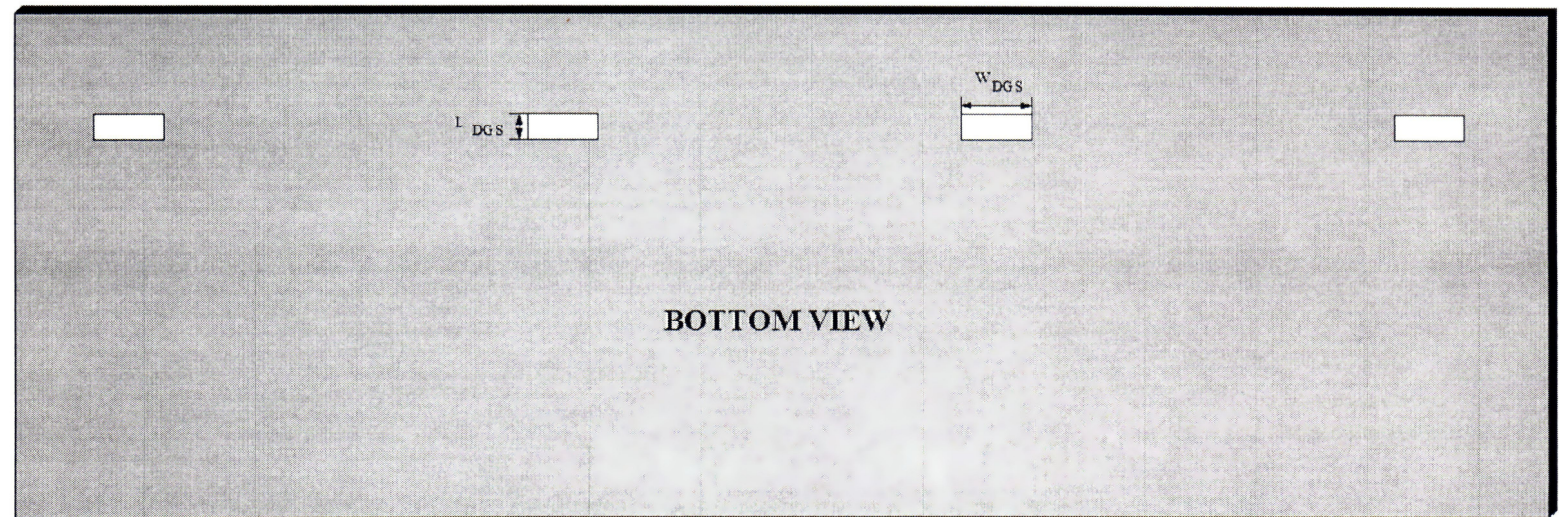

(b)

Fig. 2. Geometry of antenna 2 (a) Top view, (b) Bottom view

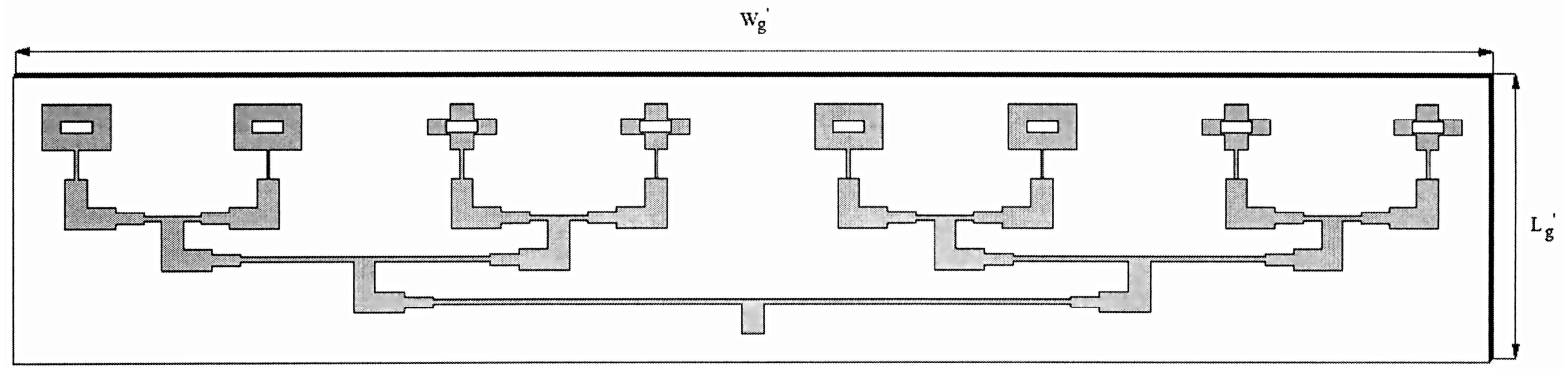

Fig. 3. Geometry of antenna 3

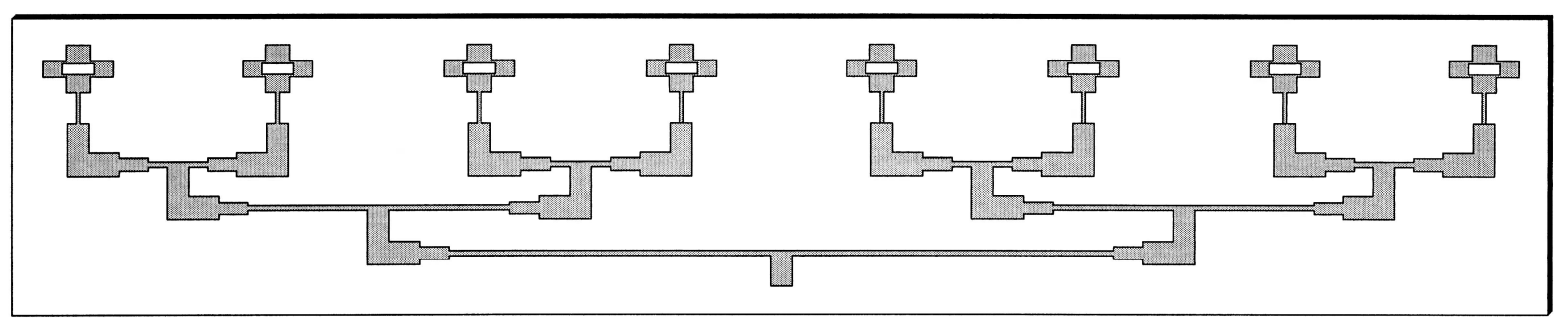

Brazilian Microwave and Optoelectronics Society-SBMO received 1 June, 2010; revised 7 Oct., 2010; revised 10 Jan., 2011; 
Fig. 4. Geometry of antenna 4

The study is extended for 8-element rectangular microstrip array antenna with DMS and DGS as shown in Fig. 3 (referred as antenna 3). Further, Fig. 4 shows the geometry of 8-element rectangular microstrip array antenna with all the radiating elements modified by inserting DMS and DGS (referred as antenna 4). Fig. 5 shows the photo of all the proposed antennas.

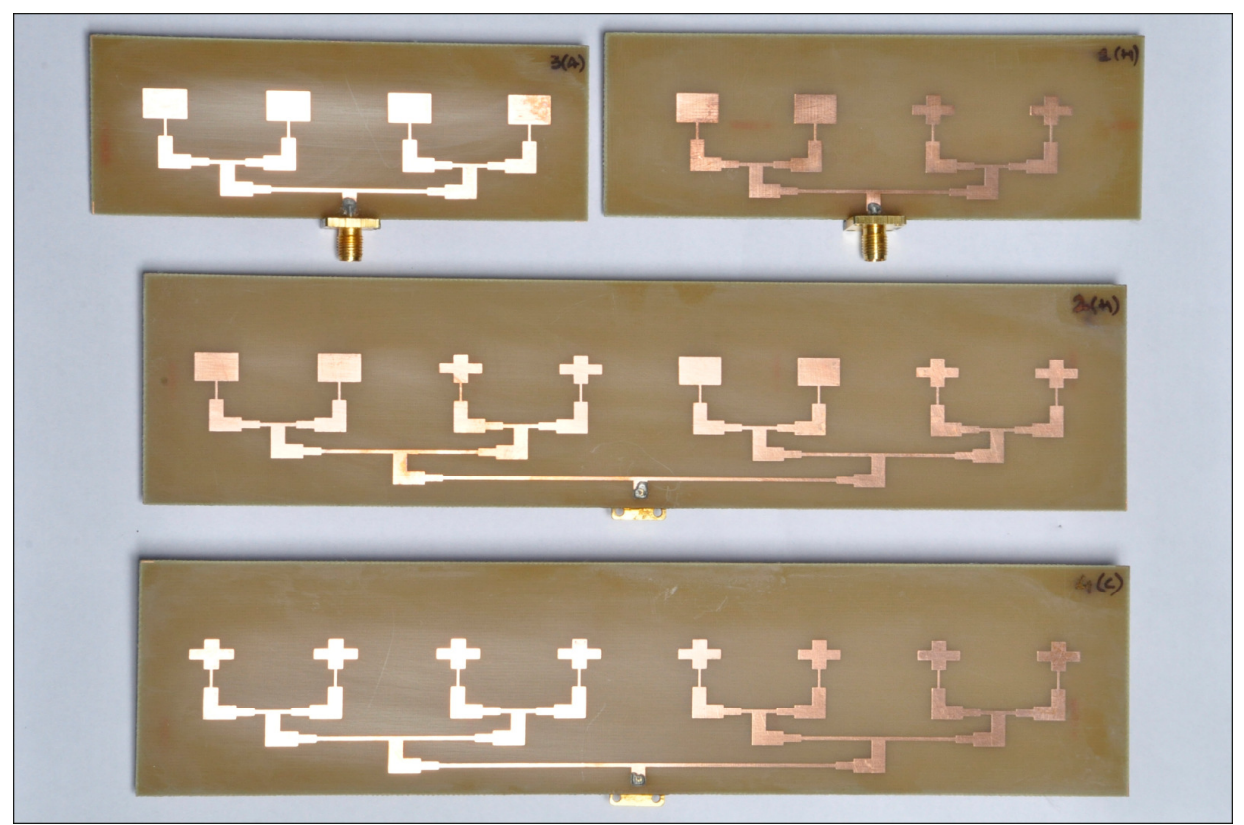

(a)

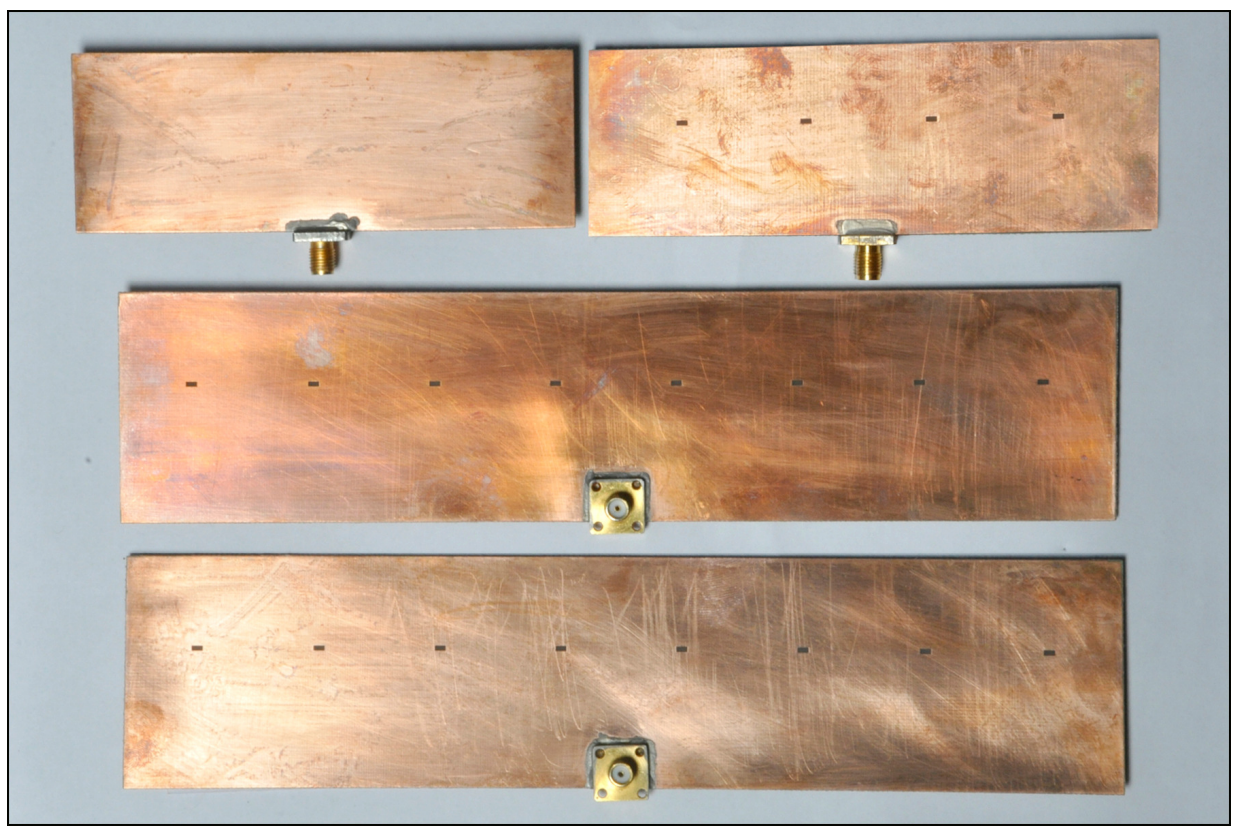

(b)

Fig. 5. Photo of all the proposed antennas (a) Top view, (b) Bottom view 


\section{EXPERIMENTAL RESULTS AND DISCUSSION}

The impedance bandwidths for the proposed antennas are measured at 4 to $18 \mathrm{GHz}$ frequencies. The measurements are taken on Vector Network Analyzer (Rohde \& Schwarz, German make ZVK Model No. 1127.8651). The variation of return loss versus frequency of antenna 1 and antenna 2 are shown in Fig. 6. The variation of return loss versus frequency of antenna 3 and antenna 4 are shown in Fig. 7.

From Fig. 6, it is observed that the antenna 1 is resonating for three bands at $10.63 \mathrm{GHz}, 12.74 \mathrm{GHz}$ and $14.63 \mathrm{GHz}$ with magnitude $600 \mathrm{MHz}(5.64 \%), 630 \mathrm{MHz}(4.94 \%)$ and $910 \mathrm{MHz}(6.21 \%)$. From the figure it is clear that the antenna 2 is resonating for six bands at $6.87 \mathrm{GHz}, 8.44 \mathrm{GHz}, 10.47 \mathrm{GHz}$, 12.47 GHz, $14.15 \mathrm{GHz}$ and $16.56 \mathrm{GHz}$ with magnitude $280 \mathrm{MHz}(4.05 \%), 1160 \mathrm{MHz}(13.38 \%), 520$ $\mathrm{MHz}(4.92 \%), 420 \mathrm{MHz}$ (3.36 \%), $490 \mathrm{MHz}(3.46 \%)$ and $1440 \mathrm{MHz}(8.50 \%)$. This increase in the number of bands is due to inserting DMS and DGS, the impedance bandwidth of the antenna is also improving and antenna is resonating at lower frequencies causing increase in bands with improved bandwidth.

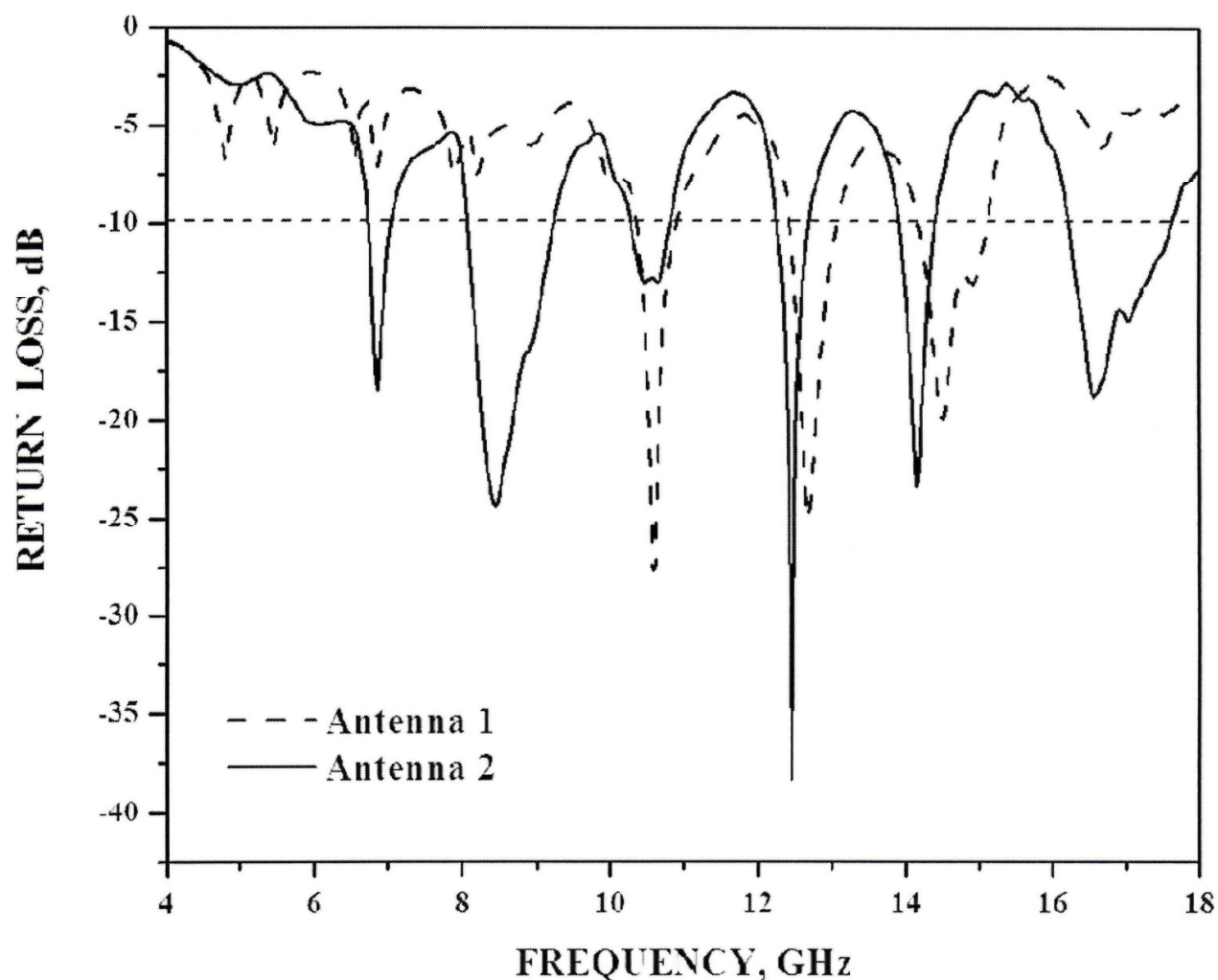

Fig. 6. Variation of Return loss V/S Frequency of antenna 1 and antenna 2

From Fig. 7, it is observe that the antenna 3 is resonating for three bands at $4.49 \mathrm{GHz}, 7.32 \mathrm{GHz}$ and $9.49 \mathrm{GHz}$ with magnitude $210 \mathrm{MHz}(4.68 \%), 2840 \mathrm{MHz}(42.32 \%)$ and $3920 \mathrm{MHz}(37.80 \%)$. This shows that, by increasing the elements of antenna 2 i.e., from 4 to 8 , the performance of the antenna also improves resulting into a small band and two wide bands operating at 4.38 to $4.59 \mathrm{GHz}$, 
5.29 to $8.13 \mathrm{GHz}$ and 8.41 to $12.33 \mathrm{GHz}$. It is clear from the graph that, the proposed antenna 3 is covering almost C-band and X-band. Further, from the graph it is observed that the antenna 4 is resonating for two bands at $4.35 \mathrm{GHz}$ and $6.03 \mathrm{GHz}$ with magnitude $420 \mathrm{MHz}(9.65 \%)$ and 5810 $\mathrm{MHz}$ (75.4\%). This shows that, inserting DMS and DGS on all 8 elements of the array will result into a small band in the range 4.14 to $4.56 \mathrm{GHz}$ and a wide band covering from 4.80 to $10.61 \mathrm{GHz}$. Hence, it is observed that by inserting DMS and DGS, the impedance bandwidth of the array antenna is improved and the antenna resonates for lower frequency when compared to antenna 1 . The minimum return loss of all the proposed antennas measured at resonating frequencies is tabulated in table II.

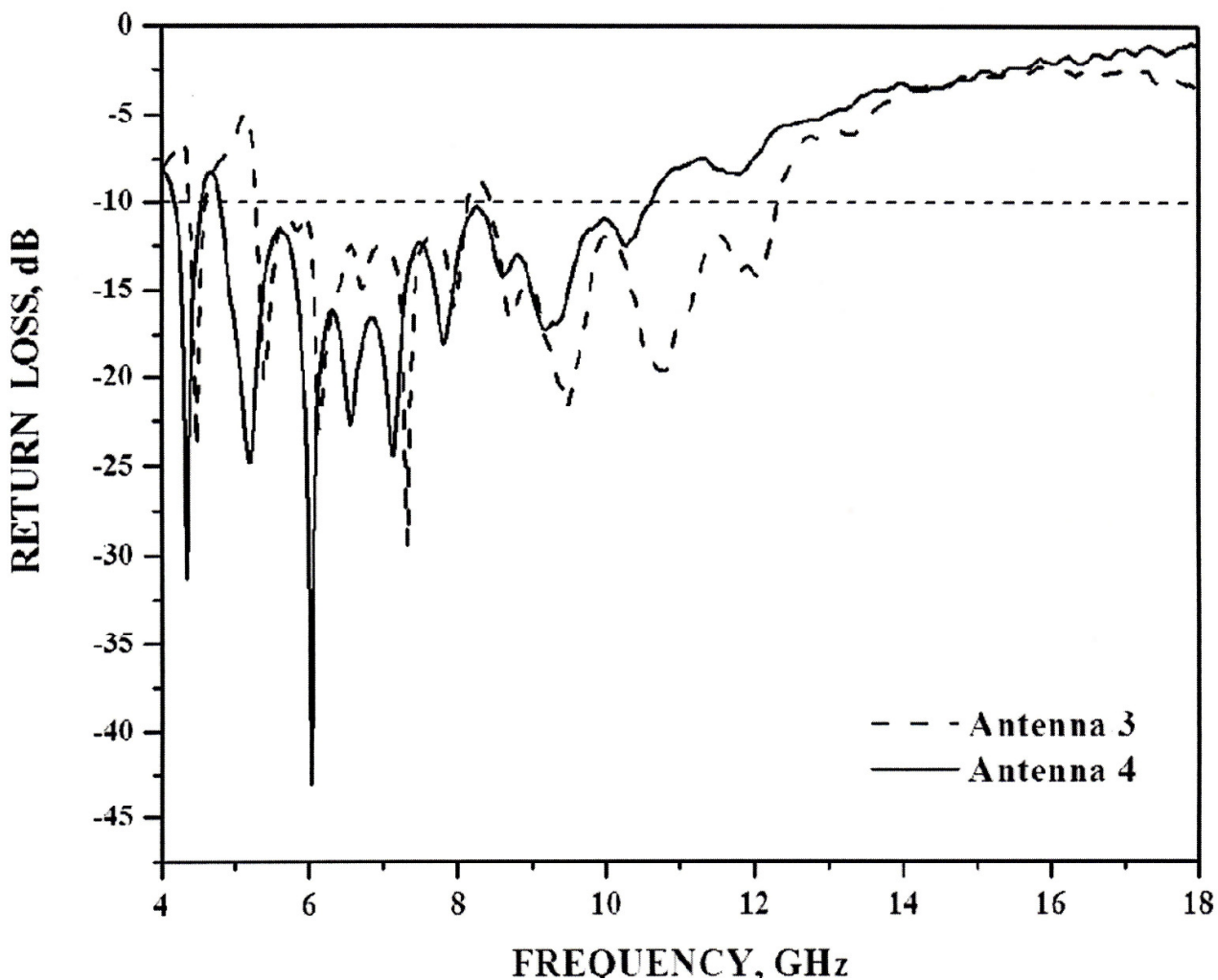

Fig. 7. Variation of Return loss V/S Frequency of antenna 3 and antenna 4

The far-field $\mathrm{H}$ - plane co-polar and cross-polar radiation patterns of all the proposed antennas are measured at their resonating frequencies. In this study the turn-table method is used to measure the radiation pattern of all the proposed antennas (AUT). Here AUT is kept in the receiving mode and the reference antenna (Pyramidal Horn) is kept in transmitting mode. The two antennas are placed so as to face each other and then, keeping the position of transmitting antenna fixed, the receiving antenna is rotated around axis, by changing the angle in steps of degrees. At each angle the received power is measured. The graph is plotted for azimuth angle versus normalized power.

Fig. 8 to Fig. 10 show the radiation patterns of antenna 1, Fig.11 to Fig. 16 show the radiation patterns of antenna 2 and Fig. 17 to Fig. 19 show the radiation patterns of Antenna 3. These figures indicate that all the antennas show broadside radiation characteristics. From Fig. 20 and Fig. 21 it is 
seen that by inserting DMS and DGS on all the 8 elements of the array, the radiation characteristic of the antenna is improved as unidirectional pattern of the antenna is converted to omni-directional. The side lobe levels and cross polarization levels of all the antennas at the resonating frequencies are measured and are mentioned in table II. At some frequencies, the proposed antennas show split beam radiation patterns which are useful in SAR for generating a pair of forward and backward squinted beams and provide simultaneous measurement of both the along-track and the cross-track velocities [12]. The half-power beamwidths (HPBWs) of all the proposed antennas are calculated for their resonating frequencies and are tabulated in table II for comparison. The gains of all the proposed antennas are measured at the resonating frequencies using gain comparison method [1] and are also tabulated in table II.

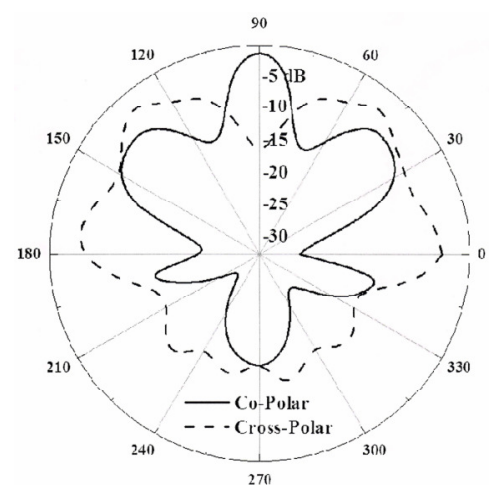

Fig. 8

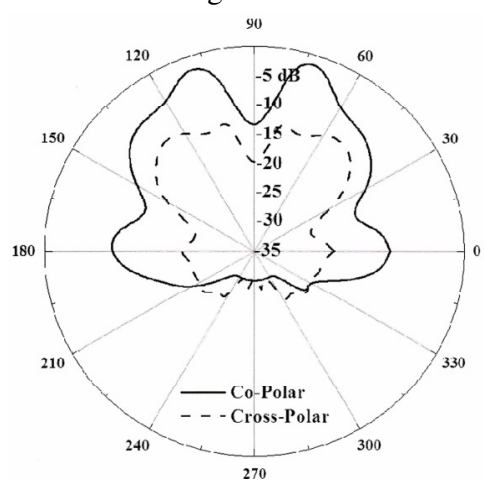

Fig. 10

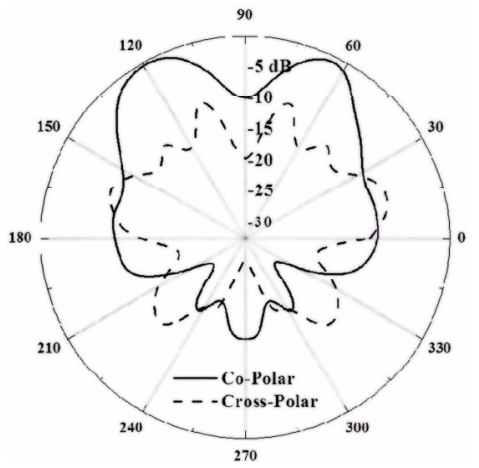

Fig. 12

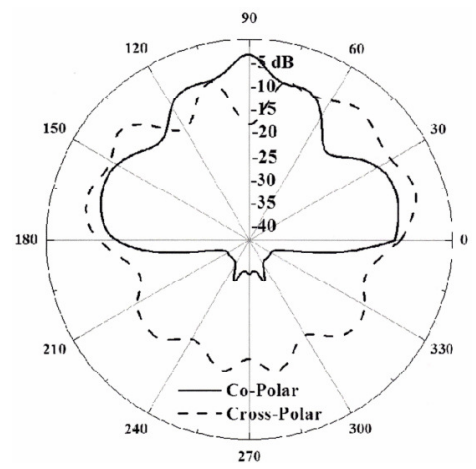

Fig. 9

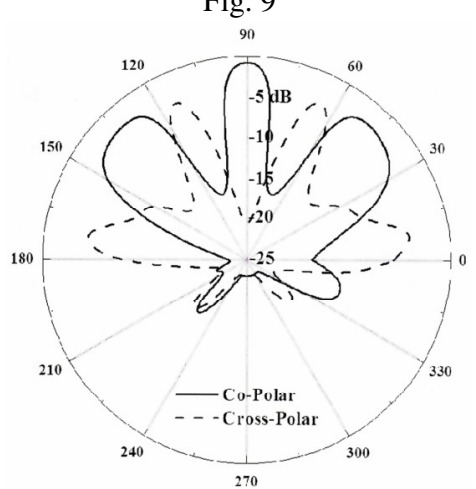

Fig. 11

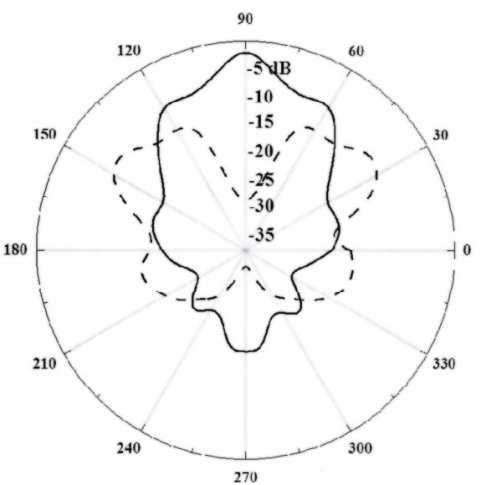

Fig. 13 


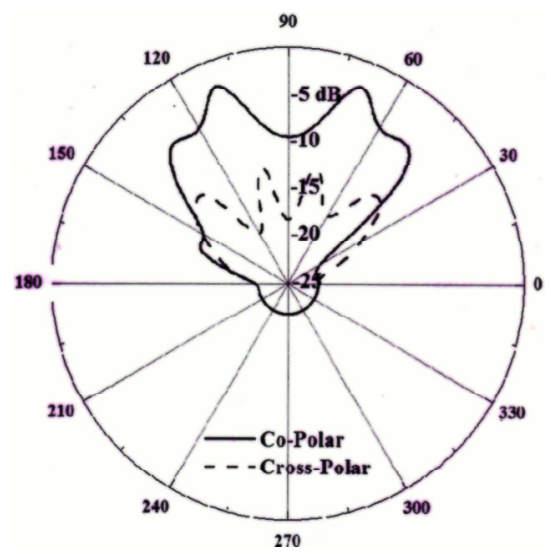

Fig. 14

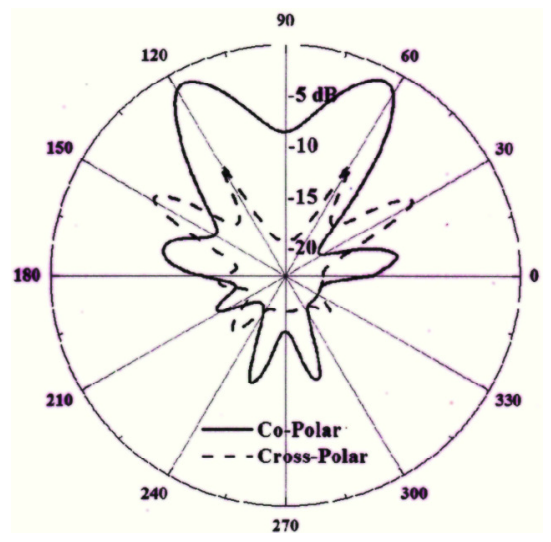

Fig. 16

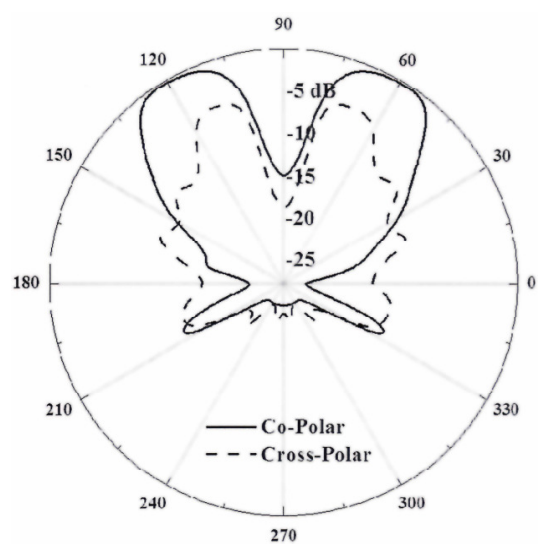

Fig. 18

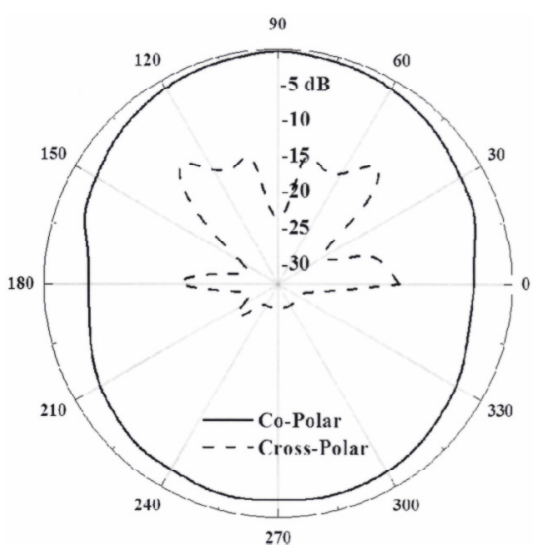

Brazilian Microwave and Optoelectronics Society-SBMO Brazilian Society of Electromagnetism-SBMag

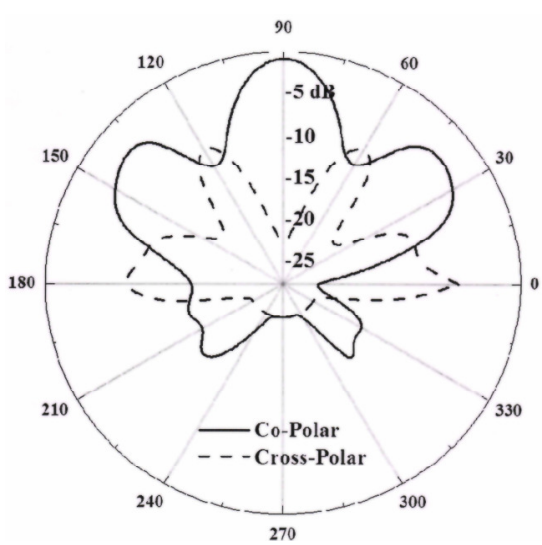

Fig. 15

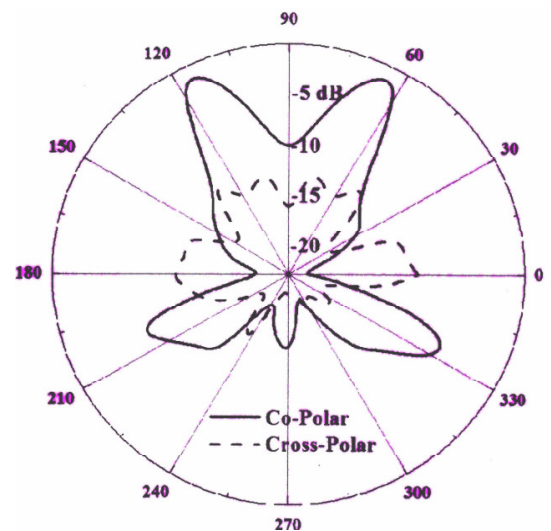

Fig. 17

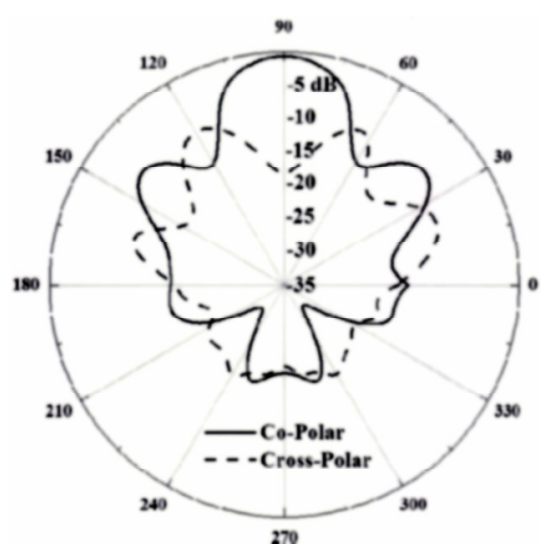

Fig. 19

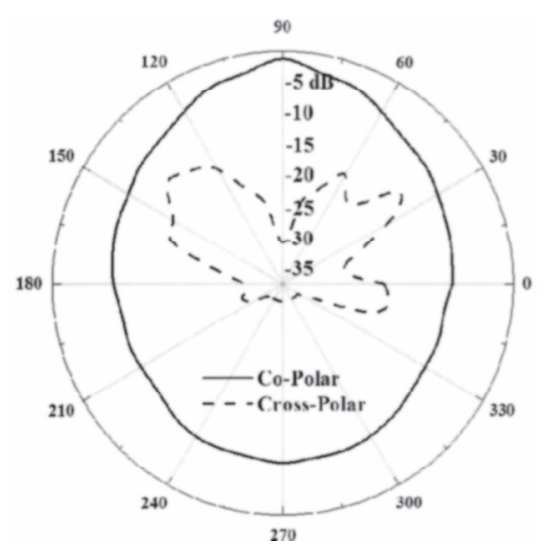

received 1 June, 2010; revised 7 Oct., 2010; revised 10 Jan., 2011; accepted 18 Jan., 2011

(C) 2011 SBMO/SBMag

ISSN 2179-1074 
Fig. 20

Fig. 21

TABLE II - MEASURED RETURN LOSS, SIDE LOBE LEVEL, CROSS-POLAR LEVEL, GAIN AND CALCULATED HPBW WITH RESPECT TO RESONATING FREQUENCIES

\begin{tabular}{|c|c|c|c|c|c|c|c|}
\hline Antenna & $\begin{array}{c}\text { Resonating } \\
\text { Frequency } \\
\text { in GHz }\end{array}$ & $\begin{array}{c}\text { Minimum } \\
\text { Return } \\
\text { loss in dB }\end{array}$ & $\begin{array}{c}\text { Side lobe } \\
\text { level in } \mathrm{dB}\end{array}$ & $\begin{array}{c}\text { Cross- } \\
\text { polarization } \\
\text { level in } \mathrm{dB}\end{array}$ & $\begin{array}{l}\text { Gain } \\
\text { in dB }\end{array}$ & HPBW & $\begin{array}{c}\text { Input } \\
\text { Impedance }\end{array}$ \\
\hline \multirow{3}{*}{ Antenna 1} & 10.63 & -27.5 & -10 & -10 & 6.26 & $11^{0}$ & $53.61+j 1.89$ \\
\hline & 12.74 & -25 & -7 & -10 & 3.14 & $18^{0}$ & $45.45+j 2.11$ \\
\hline & 14.63 & -20 & --- & -14 & --- & Split Beam & $43.22+j 6.79$ \\
\hline \multirow{6}{*}{ Antenna 2} & 6.87 & -18.42 & $\begin{array}{c}\text { Mutual } \\
\text { Coupling }\end{array}$ & -5 & --- & $\begin{array}{c}\text { Mutual } \\
\text { Coupling }\end{array}$ & $51.21-j 13.97$ \\
\hline & 8.44 & -24.41 & --- & -11 & --- & Split Beam & $63.30-j 3.48$ \\
\hline & 10.47 & -13.01 & --- & -16 & 8.76 & $12^{0}$ & $51.56+j 176.0$ \\
\hline & 12.47 & -38.38 & --- & -14 & & Split Beam & $46.84+j 5.15$ \\
\hline & 14.15 & -23.41 & -8 & -10 & 6.74 & $23^{0}$ & $50.47+j 1.42$ \\
\hline & 16.56 & -18.78 & --- & -12 & --- & Split Beam & $46.35-j 12.66$ \\
\hline \multirow{3}{*}{ Antenna 3} & 4.49 & -23.96 & ---- & -13 & --- & Split Beam & 52.59-j6.39 \\
\hline & 7.32 & -29.52 & $\begin{array}{ll}--- \\
\end{array}$ & -7 & --- & Split Beam & $46.74-j 1.28$ \\
\hline & 9.49 & -21.73 & -17 & -12 & 5.84 & $43^{0}$ & $42.52+j 2.31$ \\
\hline \multirow{2}{*}{ Antenna 4} & 4.35 & -31.37 & $\begin{array}{c}\text { Omni- } \\
\text { directional }\end{array}$ & -15 & 10.62 & $115^{0}$ & $52.77+j 92.59$ \\
\hline & 6.03 & -43.06 & $\begin{array}{c}\text { Omni- } \\
\text { directional }\end{array}$ & -20 & 15.17 & $19^{0}$ & $52.18+j 2.58$ \\
\hline
\end{tabular}

\section{CONCLUSION}

A new design has been developed using DMS and DGS. The rectangle shape DMS and DGS have been used for 4 and 8 element rectangular microstrip antenna array. The results demonstrate that impedance bandwidth and radiation properties of the antennas are improved by increasing the array elements with DMS and DGS. These antennas are more superior as these are fabricated using low cost substrate material. These antennas are more suitable for modern communication systems and in radar systems like SAR for tracking the target as soon as finding them and for anti-jamming.

\section{ACKNOWLEDGMENT}

We thank the authorities of Department of Science and Technology (DST), Govt, of India, New Delhi, for sanctioning Vector Network Analyzer under the FIST Programme to the Department of Applied Electronics, Gulbarga University, Gulbarga.

\section{REFERENCE}

[1] C. A. Balanis, “Antenna theory, analysis and design”, John Wiley and Sons. Inc., New York, 1982.

[2] D. M. Pozar, "Microstrip antennas”, IEEE Proc. Antenna Propag., vol. 80, pp. 79-81, 1992.

[3] Kim, C. S., J. I. Park, A. Dal, et. al., "A novel 1-D periodic defected ground structure for planer circuits", IEEE Microwave Guided Wave Lett., vol. 10, no. 4, pp. 131-133, 2000.

[4] A. K. Shrivastav, Promad Kumar, Jugal Kishor, Rashid Mahmood, "Impedance BW enhancement technique in microstrip circuits by using DGS and DMS”, Int. Symp. on Microwave and Optical Tech. New Delhi, pp. 532-535, 2009.

[5] F. Y. Zulkifi, et.al., "Radiation properties enhancement of triangular patch microstrip antenna array using hexagonal defected groung structure," Progg. In Electromagnetics Research M, vol. 5, 101-109, 2008. 
[6] Bahl I J and Bharatia P, “Microstrip Antennas”, Artech House, New Delhi, 1981.

[7] Kai Fong Lee \& Weichen, “Advances in Microstrip and Printed Antennas”, John Wiley, New York, 1997.

[8] Jeong Kim I I and Young Joong Yoon, "Design of wideband microstrip array antennas using the coupled lines," IEEE Antenna and Prop. Soci. Int. Symp., vol. 3, pp. 1410-1413, 2000.

[9] Oing X M and Chin Y W M, "Circularly polarized circular ring slot antenna fed by stripline hybrid coupler," Electron Lett., vol. 35, no. 25, pp. 2145-2155, 1999.

[10] S. L. Mallikarjun, R. G. Madhuri, S. A. Malipatil and P. M. Hadalgi, Compact high gain multi frequency antenna, IEEE-Int. Symp. on Microwaves 2008, Bangalore, IND,pp. 369-373, 2008.

[11] S. L. Mallikarjun, R. G. Madhuri and P. M. Hadalgi, "Effect of rectangular DGS on rectangular microstrip patch array antenna", Int. Symp. on Microwave and Optical Tech. New Delhi, pp. 257-260, 2009.

[12] John Huang and Soren N. Madsen, "A dual beam microstrip array antenna", IEEE Antenna and Prop. Soci. Int. Symp., Chicago, vol. 1, pp. 147-150, 1992. 